\title{
O presente e o passado dos planos: a necessidade de aprendizagem com o compasso da/na história
}

\author{
Plans' present and future: the need of learning with the rhythm of/in history \\ El pasado y el presente de los planes: necesidad de aprender con el ritmo de la historia
}

\author{
CANDido AlBerto GOMES* \\ WELLINGTON FERREIRA DE JESUS ${ }^{* *}$ \\ CARLOS ÂNGELO MENESES DE SOUSA *** \\ CléLIA DE FREITAS CAPANEMA*****
}

\begin{abstract}
RESUMO - Este trabalho focaliza dois aspectos das políticas de Estado necessárias à educação no Brasil: o regime constitucional de colaboração e os planos nacionais de educação. Num retrospecto histórico, mostra as dificuldades de aperfeiçoamento do Estado Democrático de Direito e da Federação, destacando os movimentos pendulares entre centralização e descentralização educacional. Analisa a experiência do I Plano Nacional de Educação, relacionando-a com as expectativas correspondentes e alguns processos pelos quais a legislação e a sua execução contribuem para desviar a ação governamental dos seus objetivos ou desvirtuar estes últimos. Com isso, ressalta a necessidade de aprendizagem das lições históricas para o II Plano Nacional de Educação.

Palavras-chave - Políticas educacionais. Legislação educacional. Financiamento da educação. Federação.

ABSTRACT - This paper focuses on two sides of long-range educational policies in Brazil: the constitutional dispositions regarding intergovernmental cooperation and the national educational plans. In its historical overview, this work stresses the difficulties in the improvement of the democratic state and the federation, as well as the oscillatory movement between centralization and de-centralization in education. In this context, it analyses the experience of the First National Education Plan, comparing it to the corresponding requirements. It finds that some political processes lead public policies to deviate from their goals or even to distort the latter. As a result, it is necessary to learn these historical lessons in favor of the Second National Education Plan.
\end{abstract}

Keywords - Educational policies. Education law. Education financing. Federation.

RESUMEN - Este trabajo aborda dos aspectos de las políticas de Estado necesarias a la educación en Brasil: el régimen constitucional de colaboración entre niveles de gobierno y los planes nacionales de educación. En una mirada histórica, presenta las dificultades de perfeccionamiento del Estado Democrático de Derecho y de la Federación, señalando los movimientos pendulares entre la centralización y la descentralización educacional. Hace también un análisis del Primer Plan Nacional de Educación en relación a sus expectativas, así como de algunos procesos por los cuales la legislación y su práctica contribuyen para desviar la acción gubernamental de sus objetivos o distorsionar estos. En conclusión, resalta la necesidad de aprender estas lecciones históricas para el Segundo Plan Nacional de Educación.

Palabras clave - Políticas educativas. Legislación educative. Financiación de la educación. Federación.

\footnotetext{
* Doutor em Educação pela Universidade da Califórnia (Los Angeles, Califórnia, EUA) e Professor na Universidade Católica de Brasília (Brasília, DF, Brasil).E-mail:<clgomes@terra.com.br>.

** Doutor em Educação pela Universidade Federal de Goiás (Goiânia, Goiás, Brasil) e Professor na Universidade Católica de Brasília (Brasília, DF, Brasil). E-mail:<wellingtonfj@gmail.com>.

*** Doutor em Sociologia pela Universidade de Brasília (Brasília, DF, Brasil) e Professor na Universidade Católica de Brasília (Brasília, DF, Brasil). E-mail: <cangelo@ucb.br>.

**** Doutora em Filosofia da Educação pela Universidade do Sul da Califórnia (Los Angeles, Califórnia, EUA) e Professora na Universidade Católica de Brasília (Brasília, DF, Brasil).E-mail: <cleliac@uol.com.br>.
} 
O Estado democrático de Direito é difícil tanto de conquistar quanto de manter-se. $\mathrm{O}$ estabelecimento de direitos e deveres para cidadãos iguais perante a lei, bem como a orquestração de governos nacionais de modo a cumprirem as suas funções, se situam entre os maiores desafios de hoje, de ontem e de amanhã. Parece consensual que a o totalitarismo, o autoritarismo e a monocracia sejam mais fáceis de conceber e de implantar, porém a sua manutenção e as suas sequelas geram altos ônus materiais e morais, de tal modo que, após certo tempo, eles se tornam altamente indesejáveis. Como nos lembra Arendt (1991, p. 381-382), já não existe qualquer lugar "incivilizado" na terra, posto que, vivemos hodiernamente em um "mundo único" e que, lastimavelmente, só conseguimos "perceber a existência de um direito a ter direitos e de um direito de pertencer a algum tipo de comunidade organizada" em situações em que "pessoas haviam perdido esses direitos e não podiam recuperá-los devido à nova situação global".

Ao refletirmos sobre a educação como política de Estado no Brasil, nos deparamos com uma opção prévia, estabelecida pela Constituição Federal, que é o próprio pacto federativo. Refletido na redação e votação da Carta Magna, ele resulta de fatores históricos, sociais e culturais cujas raízes se estendem por séculos, ao longo de processo formativo que se delineou desde o período colonial. Portanto, não surge por acaso nem momentaneamente, mas brota devagar e conduz a determinadas opções e mudanças ao longo do tempo. Com isso, hoje o Brasil é uma complexa constelação de governos subnacionais, formando três níveis: o federal, os estaduais e os municipais. Considerando a grande população e o extenso território, desincumbir-se das funções típicas de Estado não é desafio simples. Se servem de consolo, países com maior diversidade linguística, étnica e cultural, como a Índia e a China, também constituem desafios históricos de grandes dimensões, em semelhante latitude. Embora a democracia possa vicejar tanto em Estados unitários quanto federativos, o equilíbrio entre os entes que compõem as federações é também um desafio histórico formidável, em um quadro de liberdade e responsabilidade. Equilibrar recursos, poderes e competências de maneira relativamente harmoniosa e com os melhores resultados não constitui exercício histórico simples. Administrar a competição e o conflito, mantendo a tônica da cooperação acima de tudo, em favor dos cidadãos, é como o exercício do equilibrista, mantendo no ar um número de corpos muito maior que as suas duas mãos.

Também tão desafiante quanto vital é o provimento da educação, que constitui uma semeadura a longo prazo, sem a qual se criariam fossos entre as gerações e se comprometeria o futuro. Mais sério ainda, a educação apresenta missões e interesses contraditórios: ela tanto se caracteriza como a formação comum cidadã, para quem se encontra num Estado nacional, como o Brasil, e, mais ainda, se torna cidadão de um mundo globalizado, quanto representa ainda um processo diferenciador, que filtra pessoas e grupos para ocuparem posições na estratificação social. Com a extensão crescente da longevidade, a educação se estende no tempo da vida individual, com necessidades muitas vezes inéditas, que não se restringem à educação de segunda oportunidade. Nestes dilatados horizontes temporais - e aqui se situa outra contradição, entre os ciclos eleitorais e as missões de Estado -, o imediatismo é semelhante a um cupim devorador, cujos efeitos, infelizmente, são sentidos muito tempo depois, sem que muitas vezes se possam vincular os danos aos seus responsáveis. Como um navio de grande calado, as manobras precisam ser calculadas com antecedência e executadas com perícia para se evitarem problemas futuros. À semelhança de famoso naufrágio, não se pode mudar o curso repentinamente diante de um iceberg: cumpre detectá-lo muito antes para evitar o desastre.

Por isso mesmo, no alvorecer da "modernização" do Brasil, quando a urbanização e a industrialização substitutiva de importações se estabeleceram como tônicas, a Constituição Federal de 1934 optou pela educação pública como direito do cidadão e dever do Estado, vinculando-lhe recursos públicos e estatuindo a elaboração e execução, pela primeira vez, de um plano nacional de longo prazo para a educação (JESUS, 2007, 2007a), isto é, um plano de Estado e não apenas de governo. O pioneirismo desta Carta, não por acaso, sem jogo de palavras, devido à influência dos Pioneiros da Educação Nova, foi revogado no limiar da noite do Estado Novo e reapareceu no novo dia da redemocratização do País, na Constituição Federal de 1946. A determinação de formular e seguir um plano nacional, compatível com a complexidade e os efeitos a longo prazo da educação, veio, porém, se manifestar, em novo alvorecer, na Carta Magna vigente, acolhida e pormenorizada na segunda Lei de Diretrizes e Bases da Educação Nacional. Portanto, entre dias e noites, num lento processo de mudança, firmam-se ou tentam firmar-se perspectivas compatíveis com as necessidades sociais. Cabe, de início, constatar o dilatado período de 54 anos entre as Leis Maiores de 1934 e 1988 e os 67 anos entre o primeiro mandamento constitucional nesse sentido e a aprovação do I Plano Nacional de Educação (PNE). Num mundo globalizado, em rede, entre idas e voltas, em caminhos sinuosos, chega-se a um termo, porém à custa de dilatado percurso de resistências, tornando as mudanças tão vagarosas e graduais quanto possível (cf. MERCADANTE, 1965). E, ao final, quando o Plano vira lei e se pensa ter atingido o ponto de chegada e efetiva vitória, a sua pobre execução mostra que, durante a corrida mudaram as regras e a ela se acresceram novas voltas. 


\section{O BRASIL E O SEU PÊNDULO}

Este percurso, com os seus meandros e descaminhos, remete-nos a uma série de movimentos na história constitucional brasileira, que negam a visão de uma trajetória linear e ascendente, de suposto progresso. Ao contrário, da mesma forma que dias e noites se alternam, verifica-se um pêndulo se mover entre a centralização e a descentralização desde o Império até à atualidade. A Constituição Federal (BRASIL, 1988) vigente estatuiu o pacto federativo como cláusula pétrea e considerou os Estados, o Distrito Federal e os Municípios como entes autônomos. Na educação cada categoria de entes federativos tem as suas competências, fixando o regime de colaboração entre eles para a organização dos respectivos sistemas de ensino (arts. 22, XXXIV; 24, IX; art. 211 e $\S \S)$, o que implica a existência de importantes fios horizontais, não desprezados os verticais. Contudo, como em outros países, os tempos modelam a geometria das relações intra e intergovernamentais, ora pendendo para maior, ora para menor centralização. Este movimento pendular é impulsionado pela alternância até agora do Estado Democrático de Direito e do Estado autoritário. $\mathrm{Na}$ educação em particular, nossa história constitucional espelha tais oscilações: ora a democratização lhe dedica maior relevância, descentraliza a gestão, estabelece recursos financeiros vinculados e com frequência os amplia; ora, nos períodos autoritários, ocorre o contrário (GOMES et al., 2007). A Carta vigente foi modelada em mais um período de restauro do Estado de Direito e, assim, tendeu a descentralizar política e gestão, inclusive reconhecendo os Municípios como entes federados autônomos. Assim, aos sistemas de ensino federal e estaduais de 1946 acrescentaram-se os municipais. Ao mesmo tempo, a Lei Maior estatuiu o regime de colaboração intergovernamental, o que remete a um processo cooperativo horizontal e não à hierarquia piramidal.

Do ponto de vista legislativo, a Lei de Diretrizes e Bases (BRASIL, 1996) avançou ainda mais na mesma geometria político-jurídica, porém partiram da União duas iniciativas que contribuíram fundamentalmente para que o regime de colaboração se concretizasse por meio da distribuição de recursos financeiros: o Fundef e o Fundeb. Ambos, com avanços e limitações, por meio dos recursos financeiros deram e dão corpo à colaboração entre os entes governamentais. O País, de certo modo, já havia criado órgãos com estruturas e critérios racionaisburocráticos para a arrecadação tributária, mas os critérios patrimonialistas continuavam (e continuam ainda) a nortear a alocação da despesa pública. Os dois fundos contábeis, cuja semente fora plantada, junto com a vinculação de recursos, pelos Pioneiros da Educação Nova, em particular, por Anísio Teixeira (JESUS, 2007).
Ainda na década de 1930 procurava-se estabelecer um dispositivo que redistribuísse os recursos de forma mais equitativa, como disposto na Constituição: uma política de criação de fundos ou o estabelecimento de subvinculações, conforme os estudos mais recentes. Anísio Teixeira, no início de 1930, propôs a vinculação constitucional de recursos para a instrução elementar. Além de Teixeira, foi no âmbito alvissareiro da Constituinte de 1933-1934, como mencionado acima, que o deputado João Simplício propôs uma emenda constitucional destinando fundos específicos para setores da educação pública brasileira (JESUS, 2007). A emenda constitucional do deputado classista João Simplício destinava recursos para as escolas rurais, bem como o estabelecimento de "fundos especiais" para o amparo aos estudantes carentes (CUNHA, 2001, p. 169-170). Deve-se registrar que a proposta de vinculação de recursos constitucionais para a educação brasileira teve origem na Constituinte de 1933-1934 com uma emenda de autoria de Miguel Couto (JESUS, 2007, 2007a).

Amaral (2001) demonstrou que a preocupação com a criação de um fundo de financiamento à educação primária, no Brasil, também foi objeto de estudos e propostas de Anísio Teixeira, na década de 1960. Nesse sentido, é significativo registrar que a obrigatoriedade do ensino primário se iniciou legalmente em 1961. Conforme Amaral (2001), Anísio Teixeira apresentou um modelo para o financiamento do ensino primário vigente à época, expressando a preocupação com as desigualdades econômicas e culturais reinantes entre os Municípios, que resultaria na formação desigual dos alunos, conforme o local em que vivam. A diminuição dessas desigualdades poderia ser amenizada, segundo Anísio Teixeira, com a fixação de um custo-padrão da educação que deveria ser financiado com os recursos da União, dos Estados e dos Municípios (AMARAL, 2001).

Em janeiro de 1932, Anísio Teixeira, então ocupante do cargo de Diretor de Instrução Pública do Distrito Federal, através do Decreto $\mathrm{n}^{\mathrm{O}} 3.757$ organizou e regulamentou a aplicação do Fundo Escolar do Distrito Federal. Esse fundo seria aplicado na compra de terras, construção, manutenção e infraestrutura das escolas públicas do Distrito Federal. O fundo era composto pelos seguintes recursos: doações, impostos sobre casas, diversões, corridas de cavalos, desportos e loterias, entre outros. O decreto também estabelecia que multas cobradas aos funcionários públicos fossem destinadas ao fundo e revertessem para o denunciante, caso este se tratasse de funcionário público (GANDINI, 2000; AMARAL, 2001).

No contexto dos desdobramentos históricos do financiamento, a educação, no Brasil, assumiu um caráter de significação e centralidade, a partir da segunda metade da década de 1990, com a instituição de fundos destinados à 
manutenção e ao desenvolvimento do ensino fundamental e, posteriormente, abarcando toda a educação básica, isto é, respectivamente, o Fundef e o Fundeb. Esse processo foi permeado de contradições, avanços, limitações e, especialmente, de modo mais significativo, possibilitou a participação da sociedade civil organizada, tanto nos debates quanto na elaboração e no desenvolvimento do processo.

A instituição da política de fundos para o financiamento da educação básica trouxe à tona um conjunto de: estudos; pesquisas; debates; levantamentos de resultados e impactos; discussões sobre o regime de colaboração entre os entes federativos e a sua real efetivação, expondo as ações dos governos no sentido do não cumprimento da vinculação constitucional, da má utilização dos recursos públicos e da dimensão do significado do direito à educação, como uma garantia e uma conquista da cidadania, entre outros (GIL, ARELARO, 2006).

Sob esse prisma, a política de fundos complexificou o debate no campo do financiamento da educação, na medida em que possibilitou ampla discussão sobre: a problemática dos recursos; a participação social no controle e no acompanhamento; a ação do Ministério Público (MP) e de órgãos como os Tribunais de Contas (TCs) e a Controladoria Geral da União (CGU); o fomento da pesquisa e a participação das universidades, tanto no levantamento de estudos de impacto quanto na perspectiva da capacitação e do aperfeiçoamento do magistério, além de consolidar a importância da gestão democrática e dos conselhos escolares.

Contudo, a instituição da política de fundos constituise em um processo permeado de tensionamentos, avanços e limites, inserido-se em um contexto histórico que tem origem nas primeiras décadas do século $\mathrm{XX}$, como uma perspectiva de responsabilização dos entes federativos para cumprir o dispositivo constitucional relativo à sua atribuição de concretizar o direito à instrução elementar. No entanto, a efetivação desta política ocorrerá na segunda metade da última década do século XX, em meio a um conjunto de reformas e ajustes estruturais que buscavam a redução do Estado e diminuição das políticas sociais (JESUS, 2011).

O Fundef, inicialmente, atendeu aos clamores de critérios racionais e transparentes de distribuição de recursos, de fácil compreensão, ao ponto de se ouvir de uma criança no interior do Ceará, em 1998, ante a falta de material na sua escola: "Onde estão os meus 300 reais?". Sua maior falha foi talvez o descumprimento da compensação de diferenças inter-regionais (CASTRO, 2010), em parte dadas as limitações econômico-financeiras da época. O Fundeb, por sua vez, estendeu a racionalização aos demais níveis e modalidades de ensino e educação e previu o aumento progressivo das verbas federais. Nesse sentido, a educação e a saúde avançaram mais que outros setores públicos ao se estatuírem critérios racionaisburocráticos para a despesa e definir competências, em que pesem seus enganos. Isso sem esquecer o Programa Dinheiro Direto na Escola, que, paradoxalmente, rompeu o Regime de Colaboração, transferindo recursos federais às escolas, mas racionalizando, com base na matrícula, a distribuição de recursos do salário-educação, que antes estavam sujeitos à distribuição por critérios predominantemente político-partidários.

\section{O RECURSO E O DISCURSO}

É curioso que, nessa conjuntura histórica pósConstituinte, o recurso, por meio do Fundef, de certo modo precedeu o discurso do Plano Nacional de Educação. Claro, o discurso sobre o recurso se mantém intenso e continuado, mas, apesar da segunda Lei de Diretrizes e Bases e da Lei do Fundef, em 1996, a aprovação Lei do Plano ficou para alguns anos depois, em 2001, em face de dificuldades para a formação de consenso. Embora não se possa efetuar aqui uma avaliação ampla, cabe notar não só o relativo "distanciamento" cronológico do primeiro Plano, como os vetos da área econômica a dispositivos vitais de financiamento, até certo ponto, pelo menos, explicados pelo quadrante econômico externo e interno notoriamente adverso. Daí os clamores pela execução do Plano e, para isso, pela da derrubada dos vetos, que, entretanto, permaneceram até o fim da vigência da lei, mesmo com mudanças governamentais e cenário econômico-financeiro progressivamente favorável (UNESCO, 2002). Com isso, a execução e a avaliação do mesmo se revelaram altamente problemáticas, com o Plano tendo dificuldade de encarnar na realidade, de desdobrarse em planos estaduais e municipais de educação em período adequado e mesmo de pautar as ações da União e dos entes subnacionais. Conquanto território, população e complexidade administrativa possam ser dificuldades óbvias, não são intransponíveis. Apesar disso, terminada a vigência do I Plano Nacional de Educação, o Projeto do II PNE enfrenta uma tramitação lenta e difícil, podendo dar a impressão de que, para o País, tanto faria ter ou não o ornamento, de caráter simbólico, de um plano nacional de longo prazo, um plano de Estado e não simplesmente de governo.

Os percalços enfrentados levam à indagação: que se deve esperar de um plano aprovado por lei e que, por isso mesmo, integra a lei? Parece consensual que é adequado esperar pelo menos: 1) legitimidade; 2) viabilidade; 3) cogência.

\section{A legitimidade}

O Brasil, como a América Latina, viveram na guerra fria, com governos autoritários, um período de 
planos de papel, que não reconheciam adequadamente a arena política subjacente ao planejamento e à gestão educacionais, com a dinâmica das forças em competição e conflito. A racionalidade técnica, da maior importância, era vista, frequentemente, como absoluta, sem contemplar a importância da racionalidade política e as contradições entre ambas. O planejamento e as políticas educacionais com muita frequência obedeciam ao monólogo, no qual um grupo de iluminados decidia o melhor. Era como se a sociedade e o Estado fossem um liso e tranquilo lago, no qual as definições e prioridades se impusessem pela razão técnica a elas intrínseca. Com isso, o Estado arrogavase as decisões, com elevado grau de centralização e concentração. Toda a educação ficava sujeita à burocracia pública, hiper-regulamentadora, que, aliás, a bem da verdade, antecedeu a guerra fria e em grande parte se mantém até hoje. O Estado, tanto por omissão como por excesso de ação, deixou inúmeras vezes de concorrer para as necessárias mudanças educacionais.

Os ventos democráticos alteraram este estado de coisas. As forças sociais passaram a pulsar mais ostensivamente nos órgãos governamentais, particularmente nas casas legislativas. Novos processos constitucionais e legais de consulta pública, ainda que limitados, têm sido utilizados. A negociação, não raro lenta, busca resolver os impasses e tecer consensos políticos. A sociedade civil se manifesta e muitas vezes é ouvida. Entretanto, como nem tudo são flores numa democracia aprendente, no caso do I PNE se estabeleceu vigoroso embate entre situação e oposição no Poder Legislativo. Foi necessário longo tempo para alcançar uma solução de compromisso. Com a política sendo vista como a arte do possível, tal compromisso resvalou muitas vezes para amplos enunciados e orientações, agradáveis aos olhos, mas carentes de efeitos práticos precisos e focalizados. Ou seja, a política do possível, como em tantos casos, se revelou insuficiente ante as exigências históricas. Pior seria se o embate político fosse silenciado por uma lei que o ignorasse, mas nem por isso se conseguiram respostas amplamente satisfatórias. Por outro lado, a representatividade democrática é ainda deficitária. No campo educacional, não é raro falar da maioria silenciosa. Entre a visão de quem "entende" e de quem é destinatário e necessariamente também agente da educação, se estende considerável fosso. Esta maioria é composta principalmente pelos alunos, em grande parte menores de idade e em situação de fracasso escolar, cuja "culpa" tende a ser por eles próprios internalizada. Sua voz é débil, como a de grande parte dos seus pais, com modesto nível de escolaridade, abaixo do alcançado pelos seus filhos, que consideram a educação pública como dádiva do Estado ou, mais precisamente, dos chefes políticos. Estes são problemas estruturais que o regime democrático tem a vencer.
Ainda na legitimidade, não se pode esquecer de outro hiato, entre a legislação e a execução. Necessária e salutarmente atribuídas a dois Poderes independentes (mas harmônicos), sabe-se que o Executivo, o mais vultoso dos três, tem ampla margem de arbítrio para decidir o quê, como e quando se traduzirá em atos. Se a Praça dos Três Poderes, em Brasília, é um triângulo equilátero, refletindo o pensamento da Ilustração, a realidade, aqui como em numerosos países, é a de um triângulo escaleno, cujo vértice mais importante é ocupado pelo Poder Executivo.

\section{A viabilidade}

É justo esperar de uma lei que seja viável, isto é, exequível com os recursos de que dispõem o Estado e a sociedade, sob pena de perda de legitimidade. Se o cidadão não sente as consequências da lei, esta passa a ser vista como um mundo à parte, utópico e etéreo, isolado da realidade cotidiana. É a lei "para inglês ver", não para o cidadão brasileiro fazer e ver feito. Assim se interligam legitimidade e viabilidade. No caso de um plano, apesar das divergências, parece consensual que se exijam, entre outros requisitos: a) definições claras e tangíveis de objetivos, metas, prazos e responsabilidades; b) íntima relação entre planejamento e financiamento; c) meios para ser acompanhado e avaliado pelos interessados, a começar pelo eleitor e contribuinte.

Neste caso, dentro e fora da educação, leis e planos, ao contrário de Aquiles, podem ser vulneráveis em muitas partes vitais do corpo, em relação às quais cabe se acautelar. Como se diz na gíria, detectam-se muitas maneiras de "matar o coelho" e levar boas intenções a desembocar em terreno pantanoso. Alguns vícios já tradicionais podem ser arrolados de modo exemplificativo. Quando algo é difícil, inclusive o consenso, tende-se a buscar dispositivos gerais ou vagos, difíceis de operacionalizar e, portanto, pouco úteis: estão entre eles as cartas de boas intenções, agradáveis a quase todos, que em grande parte integram leis e planos educacionais. Outro engano é a fixação de uma pletora de prioridades, de modo que não se consegue distinguir as árvores dentro da floresta. Com isso, nada acaba por ser prioritário ou o administrador de plantão escolhe as alternativas que mais the convêm. Existem ainda as responsabilidades amplas, de modo a possibilitar o jogo de empurra entre os executores, que abre caminho aos vácuos e à superposição das ações governamentais. Neste sentido a colaboração inter e intragovernamental é vital para alcançar os objetivos. Outra questão estratégica se situa nos recursos, equivocadamente confundidos com o dinheiro - e dinheiro público. Planos, processos de financiamento e orçamentos públicos precisam de compatibilidade. E também não vale usar o valor da despesa pública como evidência por si só do cumprimento 
da lei. Depende de como se gasta, em que se gasta e quando se gasta.

Não é difícil perceber que o I PNE foi vítima de vários destes percalços. Seus avaliadores encontraram graves dificuldades, pela falta de objetivos e metas claros. Claro que grande parte da realidade não se reduz a números, porém há necessidade de âncoras firmes sob pena de o navio ir contra os rochedos. Outra questão foi a escassa e pouco visível articulação do Plano com outras leis e planos nos vários níveis governamentais, inclusive leis orçamentárias anuais e plurianuais. Esta orquestração é indispensável, mesmo que a coerência interna seja difícil de alcançar. Ainda outro aspecto foi a lenta particularização do PNE em planos estaduais e municipais. Não é de admirar que, terminada a vigência do primeiro, parte considerável dos governos subnacionais não os tivesse aprovado. Mais ainda, considere-se que parte ponderável dos planos aprovados espelhou o Plano Nacional, incluindo amplas generalizações e insuficientes determinações para a ação, como se os planos em si fossem uma solução.

\section{Cogência}

Não é preciso longas discussões do Direito para compreender que uma lei é obrigatória, deve ser cumprida. Caso contrário, recai no caso de manifestos, declarações e outros documentos que podem ter alto valor, mas não são leis. Um plano aprovado por lei é lei e esta é impositiva. Neste caso, constata-se certa tradição ornamental no Brasil, como se a lei sozinha fosse milagrosa e, uma vez publicada, ela, sem maiores esforços e custos, pudesse resolver os problemas nacionais. Aqui se verifica um elo perdido ou, na educação, talvez jamais encontrado: a definição clara de responsabilidades e de incentivos e sanções para a ação. Se há uma lei, cabe saber quem deve cumpri-la e, sendo impositiva, o que acarreta obedecerlhe (incentivos) ou desobedecer-lhe (sanções). Se não cumprir a lei não traz consequências, não há porque o esforço de cumpri-la. Por isso, a necessidade de uma lei de responsabilidade educacional (GOMES, 2008), sem que ela seja mais uma lei para fazer cumprir as demais leis, o que seria mais desastroso que antes.

\section{PEDRAS de TROPEÇO}

Abordar os obstáculos aos planos de educação e, considerando a fiel execução deles, ao regime de colaboração é tratar de algumas pedras de tropeço do Brasil, que não apenas servem de tropeço, mas se constituem em pedras angulares. Considerando que a educação é parte da sociedade, não se pode ver a parte sem o todo. Por isso, os planos expõem inevitavelmente chagas da nossa formação histórica que precisamos considerar, no todo, para voltar às partes. Algumas dentre elas são:

1) A assimetria do poder de influência sobre o Estado: Nas arenas políticas os mais "vocais" e mais "preparados" são mais influentes que os outros. Conforme a frase atribuída a um personagem histórico, talvez maquiavélico e hobbesiano, "quem tem o poder o exerce". Campanhas eleitorais cada vez mais caras e sofisticadas, dependentes de estratégias de "marketing", podem levar países ocidentais ao período pós-político ou ao voto contra a democracia. O Brasil não é exceção, com agravante do patrimonialismo (MARTINS, 2011), isto é, a transformação da coisa pública em proveito particular. O que é dever e fim, como proporcionar educação, tratamento hospitalar, transporte em ambulância, se torna meio para alcançar fins pessoais. O servidor público, em cargo eletivo ou não, apesar do termo constitucional, pode se tornar servidor de si mesmo e do seu grupo. Assim, o complexo exercício de um cargo, cuja remuneração pode ser muito mais alta na iniciativa privada, passa a ser objeto de duros conflitos entre um leque de candidatos, tendo em vista atrativos que não envolvem exatamente o serviço ao público. Embora patrimonialismo e burocracia (WEBER, 1999) tenham a desvantagem de ser tipos ideais situados nas duas extremidades de uma ponte, supostamente a ser transposta pelas sociedades, falta aqui "substância popular à realidade social" (RAMOS, 1965, p. 86) para equilibrar a assimetria das influências. Afinal, o patrimonialismo se faz presente até em sociedades "desenvolvidas", mas é contido por outras forças sociais, não por generosa abdicação de vantagens.

2) O federalismo cooperativo é a exceção, não a regra: As três esferas governamentais têm competido entre si, por meio de alianças e oposições, conforme eventos e processos conjunturais, frequentemente de curto prazo (SOUZA; RAMOS; DELUIZ, 2007; GHANEM, 2010). Apoios e não apoios têm valor conforme a sua relevância a curto e médio prazos e podem ser negociados em detrimento da eficiência e da qualidade do serviço público. Desse modo, um município receberá mais verbas se apoiar o governador, enquanto a oposição ficará órfã. Pior ainda, a guerra fiscal entre entes federados lembra as pulsões de vida e morte, utilizando como moeda os incentivos fiscais, que atingem a receita de impostos, base da educação. É sabido, entretanto, que as disparidades regionais se refletem e são modeladas em grande parte pela receita do imposto de operações 
relativas à circulação de mercadorias e sobre prestações de serviços de transporte interestadual e de comunicação, vulgo ICMS (CASTRO, 2010). $\mathrm{E}$, como os poderes são desiguais, a União com frequência exerce baixa ação supletiva do ponto de vista burocrático ou racional-legal: nesta ótica não faz sentido dar algo valioso sem nada receber em troca, afinal, é "dando que recebemos" - e não no sentido da virtude da caridade. Aspectos como estes fazem de uma reforma tributária um pesadelo sucessivamente adiado, pois constitui não um pomo, mas um imenso pomar de discórdias.

3) Quanto mais vagos e mais protelados os dispositivos, melhor: As táticas e técnicas legislativas têm uma orquestra de instrumentos para proclamar habilmente valores e ações desejadas e omitir ou desviar as ações correspondentes. Por exemplo, o Regime de Colaboração, indispensável a qualquer plano nacional de educação, é autoaplicável, mas precisa ser regulamentado para não se tornar um "laissez-faire" nas negociações avulsas entre os entes federados. É preciso, como no Fundeb, um conjunto de normas e critérios claros para guiar as negociações e facilitar o entrosamento. No entanto, nem a regulamentação do regime de colaboração nem a lei complementar, prevista pela Constituição Federal, que ajustaria as mangas largas da distribuição de competências foram baixadas até hoje. Os respectivos Projetos de Lei, como alteram o que quase todos usualmente fazem, não conseguem progredir nas Casas Legislativas.

4) Outros instrumentos da orquestra ignorados pelo eleitor: Em vez de um modesto fantasma da ópera, a maior parte da orquestra e, de preferência, o seu regente e o "spalla", são invisíveis ao cidadão. Entre tais fantasmas, contam-se: a) a determinação de proposições gerais, vagas propositadamente, difíceis de decifrar, com múltiplas interpretações possíveis; b) o estabelecimento de metas impactantes, de alto valor simbólico, mas sem prover os correspondentes meios nas leis de meios, isto é, orçamentárias. $\mathrm{O} / \mathrm{s}$ autor/es da proposição têm o consolo das repercussões do símbolo, em vez do alcance das metas, se estas eram mesmo seu maior alvo; c) as disposições legislativas podem ser corretas, porém, se esvaziam porque opositores inconformados, criando um novo "round", espúrio na disputa democrática, negam no todo ou em parte os meios compatíveis, isto é, procuram fazer o tiro sair pela culatra; d) outra alternativa é prover os meios orçamentários compatíveis, mas não executá-los no todo ou em parte. Nesses casos, a alegação da falta de recursos tem sido o bordão mais frequente e desgastado; e) a execução do orçamento, mesmo com baixa inflação, passa por um funil financeiro-político que escolhe prioridades conforme a conjuntura econômica e a capacidade política de estar presente e fazer-se ouvir nos processos decisórios, o que significa que o orçamento é apenas uma meia vitória; f) no avesso das disposições gerais, com ou sem boas intenções, a pletora de minúcias pode deslocar o foco do conteúdo para as formas, de tal modo que as partes se tornam mais importantes que o todo, assim adiando as mudanças. Neste sentido, Anísio Teixeira vergastava o formalismo da educação brasileira: "Tudo legal e tudo muito ruim" (GOMES, 2010, p. 75). Seguindo a hipocrisia organizacional (BRUNSSON, 2007), por fora bela viola e por dentro pão bolorento, já que, para a perspectiva cartorial, os pormenores do processo são mais visíveis e convenientes que os resultados. E assinale-se: tais fantasmas são globais e não originais criações verde-amarelas.

5) A falta de fiscalização e controle: Recaindo também no formalismo, estas funções, sobretudo do Poder Legislativo, são de tal modo secundarizadas que a mídia costuma "avaliar" os legisladores pelo número de proposições apresentadas, muitas das quais naufragam ao saírem do porto. Uma exceção foi o Senador João Calmon, que se centrava em alterações constitucionais e espalhava mil olhos, por meio de assessores, para acompanhar as políticas e orçamentos públicos. Outro poderoso fator é a amnésia das promessas eleitorais, derivada do distanciamento entre eleitos e eleitores, pouco depois de as urnas se fecharem. Promessas se tornam muitas vezes produtos midiáticos de pronto consumo, logo esquecidas, mas não todas nem por todos. Nesses casos, é preciso contar com recursos para fazer as "cobranças", o que remete outra vez à "capacidade vocal", em parte discreta e cada vez mais exercida pelos "lobbies". Como afirma Carvalho (2005) em seu resgate sobre a história da cidadania no Brasil, a ausência de ampla organização autônoma da sociedade faz com que os interesses corporativos se sobreponham. Assim, os grandes problemas da maior parte da população não são vistos ou são pouco considerados pelas representações políticas. Lamentavelmente o papel dos legisladores, para a maioria dos votantes, se reduz a intermediar favores pessoais frente ao Executivo. Cria-se assim um círculo esquizofrênico em que "o eleitor vota no deputado em troca de promessas de favores pessoais; o deputado apoia o governo em troca de cargos e verbas para distribuir 
entre seus eleitores" e "os eleitores desprezam os políticos, mas continuam votando neles na esperança de benefícios pessoais. (CARVALHO, 2005, p. 223).

Deve-se considerar que as contradições entre os papéis de cidadão, titular de deveres e direitos, e de consumidor transcendem o caso brasileiro e são também agudas em outros países, como os Estados Unidos, porém Reich (2008, p. XI) advertiu que este é "o possível destino do Brasil nos anos vindouros". Eis uma das implicações das sociedades em rede (CASTELLS, 2003).

6) A democracia é difícil, o autoritarismo é fácil: Democracia e autoritarismo são comparáveis às portas estreita e larga, que levam, respectivamente, a destinos melhores e piores. Sari (2009) identifica, na experiência do Rio Grande do Sul, o quanto uma cultura prévia de colaboração mútua e a organização institucional dos municípios facilitam concretizar o Regime de Colaboração, pautado por legislação e normas, embora ainda uma estratégia em construção. Os diálogos e pactos são demorados e complexos, mas, como é usual em política, o debate aberto continua a ser a melhor base para acordos duradouros. E outros Estados, além do Rio Grande do Sul, cuja formação histórica é diversa, têm avançado neste sentido. A opção de não avançar é alguém preencher o espaço, como deixaram claro Souza, Ramos e Deluiz (2007).

\section{PNE: PROMESSA SEGURA?}

São muitos os obstáculos que se defrontam em diferentes tempos históricos e países. Há uma tendência de superestimar os nossos desafios em relação a tempos anteriores e a lugares distantes, entretanto, um país que se considera emergente e deseja cumprir mais saliente papel histórico no mundo precisa fazer face a uma série de problemas fundamentais, entre eles o faz de conta da legislação, a educação ruim e desigual e a perspectiva cíclica eleitoral. Para ser país emergente - e não residual -, cumpre ver longe. Nesse sentido, o PNE e o indispensável Regime de Colaboração, vivência do Estado federativo em regime democrático, precisam ser compreendidos, sobretudo, na dimensão de Políticas de Estado (DOURADO, 2010, OLIVEIRA, 2011). Em outras palavras, se situam como processos que envolvem, além do Poder Executivo. outros Poderes e Instituições que representem o Estado e a sociedade. Ademais, se vinculam às demandas dos setores majoritários da sociedade, em geral mais distanciados das políticas públicas.

Dessa forma, além de serem processos estabelecidos legal e constitucionalmente, o PNE e o Regime de Colaboração devem se articular e se interconectar, ultrapassando os limites, tanto temporais, quanto de proposta de um grupo, ou um governo. Cabendo aos governos a execução de ambos.

Oliveira e Souza (2010, p. 14), ao discutirem a questão histórica entre federalismo e educação no Brasil, afirmaram que essa "tensão entre centralização e descentralização e a forma de colaboração ou relacionamento entre a União e os demais entes federados é fundamental para compreender-se a política educacional". Nesse sentido, pode-se considerar que, entre outros aspectos, vive-se no Brasil do início do século XXI uma espécie de regime de colaboração centralizado, em que o Governo Federal exerce, por meio das avaliações, uma função estratégica na coordenação de políticas, induzindo e controlando programas e ações (OLIVEIRA; SOUZA, 2010).

Abrúcio (2010) observou a impossibilidade de se implementar políticas, especialmente no ensino fundamental, sem um efetivo regime de colaboração entre Estados e Municípios, na medida em que se instalou, a partir do anos 1990, uma lógica de redistribuição de recursos, inicialmente no ensino fundamental, a partir do Fundef, e, em toda a educação básica, a partir do Fundeb. Nesse sentido, o PNE, compreendido como política de Estado, estabeleceria não apenas metas e estratégias, mas políticas, processos e a abertura à participação e controle social no setor educacional brasileiro.

Portanto, as aspirações a uma posição historicamente saliente no mundo dependem de muito esforço e, sobretudo, de saber para onde se quer ir efetivamente. Não serão somente a extensão do território, o tamanho da população, o valor do Produto Nacional Bruto ou as riquezas potenciais que assegurarão um papel de relevo. Nesse bojo, ver e transformar a educação a longo prazo é questão axial. A educação reflete ao mesmo tempo que contribui para fazer o futuro. Olhando para trás, para o que fizemos e deixamos de fazer, um país pode aprender com os seus acertos e erros. No que tange ao II PNE, precisamos aprender, em particular, as lições da elaboração e execução do Primeiro. Passou-se mais de uma década num período de aceleração da História e não temos o direito de perder mais uma. Com essa aprendizagem, o PNE pode se tornar uma promessa segura e não vã, capaz de alimentar a confiança e a esperança.

\section{REFERÊNCIAS}

ABRÚCIO, Luiz Fernando. A dinâmica federativa da educação brasileira: diagnóstico e propostas. In: OLIVEIRA, Romualdo Portela de; SANTANA, Wagner. (Org.). Educação e federalismo no Brasil: Combater as desigualdades, garantir a diversidade. Brasília: Unesco, p. 39-70, 2010. 
AMARAL, Nelson Cardoso do. Um novo Fundef? As idéias de Anísio Teixeira. Educ. Soc., Campinas, v. 12, n. 75, p. 22-290, ago. 2001

ARENDT, Hannah. Origens do totalitarismo. São Paulo: Companhia das letras. 1991.

BRASIL. Presidência da República. Constituição da República Federativa do Brasil de 1988. Disponível em: <http://www. planalto.gov.br/ccivil_03/constituicao/Constituicao.htm>. Acesso em: 02 maio $20 \overline{1} 2$.

BRASIL. Presidência da República. Lei no 9.394, de 20 de dezembro de 1996. Disponível em: <http://www.planalto.gov. br/ccivil_03/leis/L9394.htm>. Acesso em: 25 abr. 2012.

BRUNSSON, Nils. The consequences of decision-making. Oxford: Oxford University Press, 2007.

CARVALHO, José Murilo de. Cidadania no Brasil: O longo caminho. 7. ed. Rio de Janeiro: Civilização Brasileira, 2005.

CASTELLS, Manuel. A sociedade em rede. 7. ed. São Paulo: Paz e Terra, 2003.

CASTRO, Jorge Abrahão. Financiamento da educação pública no Brasil: evolução dos gastos. OLIVEIRA, Romualdo Portela de; SANTANA, Wagner (Org.). Educação e federalismo no Brasil: combater as desigualdades, garantir a diversidade. Brasília: UNESCO, 2010. p. 169-190. Disponível em: <http:// unesdoc.unesco.org/images/0018/001873/187336por.pdf $>$. Acesso em: 25 abr. 2012.

CUNHA, Alexandre Sanches. Todas as Constituições brasileiras. Campinas, SP: Bookseller, 2001.

DOURADO, Luiz Fernandes. Avaliação do Plano Nacional de Educação 2001-2009: questões estruturais e conjunturais de uma política. In: Educ. Soc., Campinas, v. 31, n. 112, p. 677-705, jul.-set. 2010.

GANDINI, Regina P. C. Anísio Teixeira e a burocracia (1931 a 1935). In: SMOLKA, Ana Luíza Bustamonte; MENEZES, Maria Cristina (Org.). Anísio Teixeira, 1990-2000 - provocações em educação. Campinas, SP: Autores Associados, 2000.

GIL, Juca Pirama C; ARELARO, Lisete Regina. Política de fundos na educação: duas posições. In: LIMA, M. J. R.; DIDONET, Vital (Org.). FUNDEB - avanços na universalização da educação básica. Brasília: MEC-INEP, p. 71-88, 2006.

GOMES, Candido Alberto et al. O financiamento da educação brasileira: uma revisão da literatura. Revista Brasileira de Política e Administração da Educação, Porto Alegre, v. 23, n. 1, p. 29-52, jan.-abr. 2007.

GOMES, Candido Alberto. Fundamentos de uma lei de responsabilidade educacional. Brasília: UNESCO, 2008. Disponível em: <http://unesdoc.unesco.org/Ulis/cgibin/ulis.pl ?gp $=0 \&$ look $=$ zh \&sc $1=1 \&$ by $=3 \&$ au $=$ Gomes, $\% 20$ Candido $\% 20$ Alberto $>$. Acesso em: 17 maio 2013.

GOMES, Candido Alberto. Darcy Ribeiro. Recife: Massangana/ FNDE, 2010. Disponível em: < http://www.dominiopublico.gov. br/download/texto/me4696.pdfhttp://www.dominiopublico. gov.br/download/texto/me4696.pdf> . Acesso em: 25 abr. 2012.
JESUS, Wellington Ferreira de. A política de fundos constitucionais no contexto da Educação Básica no Brasil: origens, contradições e perspectivas. 2011. Tese (Doutorado em Educação) - Universidade Federal de Goiás, Goiânia, 2011.

JESUS, Wellington Ferreira de. O "problema nacional": a história de uma Emenda que transformou o financiamento da educação no Brasil. Revista Brasileira de Estudos Pedagógicos, v. 220, p. 471-495, 2007.

JESUS, Wellington Ferreira de. "Despesa Sagrada": estudo sobre a vinculação constitucional de verbas a educação nas Constituições Brasileiras de 1934 e 1946. 2007a. Dissertação (Mestrado em Educação) - Universidade Católica de Brasília, Brasília, 2007a.

MARTINS, Paulo de Sena. Fundeb, federalismo e regime de colaboração. Campinas, SP: Associados; Brasília: Universidade de Brasília, 2011.

MERCADANTE, Paulo. Consciência conservadora no Brasil. Rio de Janeiro: Civilização Brasileira, 1965.

OLIVEIRA, Romualdo Portela de; SOUZA, Sandra Zákia. Federalismo e sua relação com a educação no Brasil. In: OLIVEIRA, Romualdo Portela de; SANTANA, Wagner (Org.). Educação e federalismo no Brasil: Combater as desigualdades, garantir a diversidade. Brasília: Unesco, p. 13-38, 2010 .

OLIVEIRA, Dalila Andrade. Das políticas de governo a política de estado: reflexões sobre a atual agenda educacional brasileira. In: Educ. Soc., Campinas, v. 32, n. 115, p. 323-337, abr.-jun. 2011.

RAMOS, Alberto Guerreiro. A redução sociológica. 2. ed. Rio de Janeiro: Tempo Brasileiro, 1965.

REICH, Robert Bernard. Supercapitalismo: como o capitalismo tem transformado os negócios, a democracia e o cotidiano. Rio de Janeiro: Elsevier, 2008.

SARI, Marisa Timm. Regime de colaboração intergovernamental em educação: a experiência do Rio Grande do Sul. 2009. 199 fls. Dissertação (Mestrado em Educação) Universidade Federal do Rio Grande do Sul, Porto Alegre, 2009.

SOUZA, Donaldo Bello de; RAMOS, Marise Nogueira; DELUIZ, Neise. Cobertura municipal da educação profissional via regime de colaboração: uma prática possível? Ensaio: Avaliação em Políticas Públicas em Educação, Rio de Janeiro, v. 15 , n. 54, p. 29-52, jan.-mar. 2007.

UNESCO. Traduzindo em ações o PNE. Brasília: UNESCO, 2002.

WEBER, Max. Economia e sociedade: fundamentos da sociologia compreensiva. 4. ed. Brasília: Ed. Universidade de Brasília; São Paulo: Imprensa Oficial, 1999. v. 1.

Artigo recebido em janeiro 2014.

Aprovado em junho 2014. 